\title{
Dynamic Portfolio Selection on Croatian Financial Markets: MGARCH Approach
}

\author{
Tihana Škrinjarić, Boško Šego
}

Faculty of Economics and Business, University of Zagreb, Croatia

\section{Abstract}

Background: Investors on financial markets are interested in finding trading strategies which could enable them to beat the market. They always look for best possibilities to achieve above-average returns and manage risks successfully. MGARCH methodology (Multivariate Generalized Autoregressive Conditional Heteroskedasticity) makes it possible to model changing risks and return dynamics on financial markets on a daily basis. The results could be used in order to enhance portfolio formation and restructuring over time. Objectives: This study utilizes MGARCH methodology on Croatian financial markets in order to enhance portfolio selection on a daily basis. Methods/Approach: MGARCH methodology is applied to the stock market index CROBEX, the bond market index CROBIS and the kuna/euro exchange rate in order to model the co-movements of returns and risks on a daily basis. The estimation results are then used to form successful portfolios. Results: Results indicate that using MGARCH methodology (the CCC and the DCC model) as guidance when forming and rebalancing a portfolio contributes to less portfolio volatility and greater cumulated returns compared to strategies which do not take this methodology into account. Conclusions: It is advisable to use MGARCH methodology when forming and rebalancing portfolios in terms of portfolio selection.

Keywords: Zagreb Stock Exchange, DCC and CCC GARCH, risk hedging, volatility JEL classification: G12, C58

Paper type: Research article

Received: Jan 20, 2016

Accepted: Jul 21, 2016

Citation: Škrinjarić, T., Šego, B. (2016), "Dynamic portfolio selection on Croatian financial markets: MGARCH approach", Business Systems Research, Vol. 7, No. 2, pp. 78-90.

DOI: 10.1515/bsrj-2016-0014

\section{Introduction}

When making investment decisions, investors consider risk and return (among other topics) of financial assets as major factors which influence their decisions in portfolio selection. However, it is long known that asset returns and risks depend one on another and that they move together across markets and time (see Bekaert, Hodrick and Zhang (2009) or Bauwens, Laurent and Rombouts (2006) for extensive list of papers which agree on this topic). This means that risk and return modelling has to take into consideration that individual risks and returns cannot be modelled separately. Instead, we need to take into consideration these facts. That is why in the 
last two decades there has been a rise in modelling financial market movements by using MGARCH methodology. MGARCH stands for Multivariate Generalized Autoregressive Conditional Heteroskedasticity, which means that we are modelling more than one asset risk and return simultaneously. Since financial markets exhibit specific characteristics which distinguish them from other markets (see Aielli 2013, Alexander 2008, Lüketpohl 2006, Enders 2015, etc. for details), GARCH methodology has become an imperative when considering financial data.

In the last decade, multivariate modelling of risk and return is emerging as the main methodology (see Clements et al. 2012) to consider when looking at financial data because literature has observed that financial assets move together across markets and time. Volatilities (risks) transmit from one market to another. Proof is provided in the growing literature in this field. Most of the literature is focused on looking volatility transmissions between countries (see Hernández, Ibarra-Ramírez and Trupkin 2011 or Robbani, Bhuyan and Sbelti 2013 for more detalis). Majority of research has focused on developed markets. In the last couple of years studies which analyze markets in transition and in development have been emerging, since we are observing Croatia as an example of a developing market in this study. Such studies include Gelos and Sahay (2001) in which they looked European transition economies; Schotman and Zalewska (2006) observed dependence between European transition economies and developed markets; Wang and Moore (2008) found that correlation rises when crisis hits financial markets by examining CEE countries; Dajčman (2013) had similar conclusions for the Croatian and selected European stock markets. Moreover, Horvath and Petrovski (2013) looked at CEE and SEE countries; Kenourgios and Samitas (2011) at Balkan emerging and selected European developed markets and Sllignakis and Kouretas (2011) CEE countries. They all had similar conclusions that there exists volatility co-movement between examined markets. This has consequences when forming international portfolios.

However, investors are interested in diversification on individual markets as well (see Škrinjarić and Šego 2015 for details). In that way, it is essential to model volatility transmissions between different sectors. When observing previous literature dealing with this issue, it can be seen that there do not exist many papers which observe this problem. Majority of existing papers focus on sector diversification on individual stock markets. Ho and Tsui (2004) examined Japanese sector indices; Hassan and Malik (2007) US indices, Righia and Ceretta (2012) Brazilian indices and Katzke (2013) South African indices. If we look at Croatian capital market, Škrinjarić (2015) focused on CAPM (Capital Asset Pricing Model) betas of five sectors on Zagreb Stock Exchange. They all concluded that MGARCH methodology is very useful when forming portfolios because there exists a relationship between sector returns and risks. What can be observed in previous analysis is that foreign papers focus on stock market sector diversification. Investors consider other financial assets as well when making their decisions about investing. That is why Škrinjarić and Šego (2015) observed stock and bond market and their interactions in Croatia. They concluded that using output from MGARCH models results with portfolios superior to other portfolios. However, they focused only on the stock and bond market. That is why this paper is going to include exchange rate market as well, in order to have a more realistic approach to investing. However, this will be more computationally difficult (details are provided in the methodology section). Since this is one of the first studies of this kind in Croatia, and on CEE countries as well, we hope to contribute to the existing literature by analyzing portfolio selection which takes into account risk-return interactions between different assets. The structure of the paper is as follows. Second section deals with methodology used in the study. Afterwards, the results of the empirical 
part of the study are shown in the third section. Discussion is given in the next section with recommendations for the future research based upon the results. The final, fifth section concludes the paper.

\section{Methodology}

MGARCH (Multivariate Generalized Autoregressive Conditional Heteroskedastiscity) models are a family of nonlinear models which are used to model co-movements of financial assets' returns and risks. Bauwens, Laurent and Rombouts (2006) concluded based upon their survey on MGARCH models that it is a widely accepted fact that financial volatilities move together across markets and time. This means that we need to use appropriate methodology which can take this into account. Lien and Tse (2002), Longin and Solnik $(1995,2001)$ agree on the usefulness of MGARCH models in portfolio selection, hedging risk and asset pricing models. Thus, a family of MGARCH models has been developed (and is still being developed) in the last two decades.

There exist different types of models within this methodology, but we can group them into three categories. The first group of models included estimating a lot of parameters in the system (VECH, diagonal GARCH) and they are a direct generalization of univariate GARCH models; the second group is a linear combination of univariate GARCH models (OGARCH, factor $\mathrm{GARCH})$ which are useful for exchange rate modelling. The last group consists of nonlinear combination of univariate GARCH models (CCC, DCC) which are the most parsimonious. Previous research on topics discussed in this paper agrees that the third group of MGARCH models is successful in capturing changing dynamics on financial markets. At the same time, they include estimating a lower number of parameters in the system which makes it computationally more feasible compared to previous two groups. That is why this study utilizes two famous models: CCC (Constant Conditional Correlation) and DCC (Dynamic Conditional Correlation) model. CCC $(1,1)$ model was developed by Bollerslev (1990) and it assumes that correlations among financial assets do not change over time. Changes in covariances are caused only by changing variances. Formally, the model can be written in a matrix form:

$$
\left.\begin{array}{l}
\boldsymbol{r}_{\dagger}=\boldsymbol{\Theta} \mathbf{x}_{\dagger}+\boldsymbol{\varepsilon}_{\dagger} \\
\boldsymbol{\varepsilon}_{\dagger}=\boldsymbol{\Omega}_{+}^{\frac{1}{2}} \boldsymbol{U}_{\dagger} \\
\boldsymbol{\Omega}_{\dagger}=\mathbf{D}_{\dagger}^{\frac{1}{2}} \boldsymbol{R D}_{\dagger}^{\frac{1}{2}}
\end{array}\right\}
$$

where the $(m, 1)$ vector of returns $\boldsymbol{r}_{t}$ is modelled by using $(m, 1)$ vector of independent variables $\mathbf{x}_{t}$ and $\boldsymbol{\Theta}(m, k)$ matrix of parameters which need to be estimated. $\boldsymbol{\varepsilon}_{f}$ is $(m, 1)$ vector of innovation processes, defined by the Cholesky factor $(m, m)$ matrix $\boldsymbol{\Omega}_{t}^{\frac{1}{2}}$ and $(m, 1)$ vector of normal i.i.d. innovations $\boldsymbol{u}_{t}$. Engle (2009) states that the assumption of multivariate normal distribution of innovations is usually made in the literature. Correctly specifying the conditional mean and variances in the model will results with consistent estimates regardless of the normality assumption. $\boldsymbol{\Omega}_{+}$is the conditional covariance $(m, m)$ matrix, defined by the $\boldsymbol{D}_{+}(m, m)$ diagonal matrix of conditional variances and $\boldsymbol{R}(\mathrm{m}, \mathrm{m})$ positive definite unconditional correlation matrix. Conditional variances in $\boldsymbol{D}_{+}$are typically modelled by univariate GARCH $(1,1)$ models:

$$
\sigma_{i, t}^{2}=a_{0, i}+a_{1, i} \varepsilon_{i, t-1}^{2}+\beta_{1, i} \sigma_{i, t-1}^{2} .
$$


Of course, it must hold: $a_{0, i}>0, a_{1, i} \geq 0$ and $\beta_{1, i} \geq 0$ so the conditional variances are positive, and $a_{1, i}+\beta_{1, i}<1$ must hold so each conditional variance is finite. As it can be seen, the model assumes that correlations are fixed over time. However, the dynamics on financial markets change on a daily basis. Thus, a model which assumes changing correlations was developed by Engle (2002), the DCC $(1,1)$ :

$$
\begin{aligned}
& \boldsymbol{r}_{t}=\boldsymbol{\Theta} \mathbf{x}_{t}+\boldsymbol{\varepsilon}_{t} \\
& \boldsymbol{\varepsilon}_{f}=\boldsymbol{\Omega}_{+}^{\frac{1}{2}} \mathbf{U}_{\dagger} \\
& \boldsymbol{\Omega}_{\dagger}=\mathbf{D}_{\dagger}^{\frac{1}{2}} \boldsymbol{R}_{t} \mathbf{D}_{\dagger}^{\frac{1}{2}} \\
& \boldsymbol{R}_{\dagger}=\operatorname{diag}\left(\boldsymbol{Q}_{\dagger}\right)^{-\frac{1}{2}} \boldsymbol{Q}_{\dagger} \operatorname{diag}\left(\boldsymbol{Q}_{\dagger}\right)^{-\frac{1}{2}} \\
& \boldsymbol{Q}_{t}=\left(1-\theta_{1}-\theta_{2}\right) \boldsymbol{R}+\theta_{1} \tilde{\boldsymbol{\varepsilon}}_{t-1} \tilde{\boldsymbol{\varepsilon}}_{t-1}^{\prime}+\theta_{2} \boldsymbol{Q}_{t-1}
\end{aligned}
$$

In this model it is assumed that the correlation matrix $\boldsymbol{R}_{f}$ is changing over time. It's dynamics is defined by $\boldsymbol{Q}_{f},(m, m)$ variance and covariance matrix of standardized innovations. $\tilde{\boldsymbol{\varepsilon}}_{f}$ is $(\mathrm{m}, 1)$ vector of standardized innovations, $\tilde{\boldsymbol{\varepsilon}}_{f}=\boldsymbol{D}^{-1} \boldsymbol{\varepsilon}_{f}$; and $\boldsymbol{R}$ is $(m, m)$ positive definite unconditional correlation matrix. Nonnegative parameters $\theta_{1}$ and $\theta_{2}$ define the dynamics of conditional correlations, with the condition $\theta_{1}+\theta_{2}<1$ for the stationarity of the model (see Engle 2002, 2009). It must also hold: $E\left(\tilde{\boldsymbol{\varepsilon}}_{+} \tilde{\boldsymbol{\varepsilon}}_{+}^{\prime}\right)=I_{m}$, where $I_{m}$ is the identity matrix, $\operatorname{Cov}\left(\tilde{\varepsilon}_{i, t}^{2}, \tilde{\varepsilon}_{j, t}^{2}\right)=0 \forall i \neq j$, and $\operatorname{Cov}\left(\tilde{\varepsilon}_{i, t}^{2}, \tilde{\varepsilon}_{j, t-k}^{2}\right)=0, k>0$ (see Ding and Engle 2001).

Estimation procedure of these models is given in two steps. In the first step univariate GARCH models are estimated in order to obtain estimates of alphas and betas in (2). In the second step these estimates are used in order to maximize the likelihood function to obtain estimates of $\theta_{1}$ and $\theta_{2}$. More on estimation procedure and details, please see Bollerslev (1990), Bollerslev and Wooldridge (1992), Ang and Chen (2005), Lüketpohl (2006), Aielli (2013), etc.

MGARCH models and their estimation results can be used in numerous ways in portfolio selection and risk hedging. Kroner and $\mathrm{Ng}$ (1998) define optimal portfolio weights of each asset in a portfolio by the following expression:

$$
\mathrm{w}_{i, t}^{*}=\frac{\sigma_{i, t}^{2}-\sum_{\substack{j=1 \\ j \neq i}}^{N} \sigma_{i j, t}}{\sigma_{i, t}^{2}-2 \sum_{\substack{j=1 \\ j \neq i}}^{N} \sigma_{i j, t}+\sum_{\substack{j=1 \\ j \neq i}}^{N} \sigma_{j, t}^{2}} .
$$

In that way, we can retrieve optimal weight for each asset in the portfolio for each analyzed day. These weights are used when calculating expected portfolio return and risk. This study is going to compare returns and risks of a portfolio based upon the results from MGARCH methodology and a portfolio which consists of equal weights of financial assets as a benchmark portfolio. The results are given in the next section.

\section{Results}

For the purpose of empirical research, daily data on index CROBEX, index CROBIS and exchange rate Kuna/Euro were downloaded from Zagreb Stock Exchange (ZSE 2015) and Croatian national bank (CNB 2015) for the period from January $4^{\text {th }} 2010$ to October $12^{\text {th }} 2015$. Thus, the sample consists of 1443 observations for each asset. It is assumed that investor is investing his resources into stocks (CROBEX), bonds (CROBIS) 
and the exchange rate. All of the estimations were performed in EViews 8. Daily returns have been calculated by using the formula:

$$
r_{i, t}=\ln \frac{p_{i, t}}{p_{i, t-1}}
$$

where $r_{i, t}$ denotes daily return on asset $i$, and $p_{i, t}$ denotes the daily value of each asset. Basic descriptive statistics for each return is given in Table 1. It can be seen that the stock market index has the highest expected return in the observed period, but the risk was the greatest for the exchange rate return. However, these and other results in Table 1 are averaged over the whole period and do not give us information on changing dynamics over time.

Table 1

Descriptive statistics for each return series

\begin{tabular}{lrrr}
\hline & CROBEX & \multicolumn{1}{c}{ CROBIS } & \multicolumn{1}{c}{ ERATE } \\
\hline Mean & 0,000029 & 0,000066 & $-0,000111$ \\
Median & 0,000038 & 0,000069 & $-0,000161$ \\
Standard Deviation & 0,000980 & 0,001715 & 0,007217 \\
Kurtosis & 1,366188 & 8,701045 & 17,718809 \\
Skewness & 0,062127 & $-0,311997$ & 0,858689 \\
Minimum & $-0,004243$ & $-0,014046$ & $-0,047763$ \\
Maximum & 0,004611 & 0,010009 & 0,085629 \\
\hline
\end{tabular}

Source: Authors

First of all, each series was filtered by an appropriate ARIMA $(p, q)$ model so the main MGARCH model can be estimated with least parameters possible. CROBEX returns were found to be $A R(2)$ process, CROBIS returns $A R M A(1,1)$ and exchange rate $A R(2)$ process. Models have been chosen based upon log likelihood values, Akaike, Hannan-Quinn and Schwartz information criterion, as well as based upon the statistical significance of independent variables in each model and model's residual diagnostics. Detailed results are available upon request. Filtered data were then used to estimate a trivariate DCC $(1,1)$ model in which parameter $\hat{\theta}_{1}$ was found to be not statistically significant. Thus, a CCC $(1,1)$ model has been estimated instead. The results from the estimation are given in Table 2.

It can be seen in Table 2 that the CROBEX return is the most sensitive to market shocks (greatest alpha $\hat{a}_{1, i}$ ), while exchange rate return is the most persistent (greatest beta) which means that the shocks from market will be present in this series for the majority of time compared to other two series. Investors can take this into account when rebalancing portfolios when good or bad shocks occur on the market. Moreover, it can be seen that the correlations are relatively small, and two out of three are negative - this is favourable for diversification purposes.

Next, covariances between each pair of assets have been calculated on a daily basis, based upon the results in Table 2. The covariances are changing over time due to changing variances of each asset. Although the correlations are constant due to the nature of the CCC model, the covariances are changing because of the changing variances. The results are given in Figure 1. The covariance between CROBEX and CROBIS was positive during the whole period, but it was very small. Other two covariances were negative which is good for portfolio diversification. 
Table 2

Estimation results of CCC $(1,1)$ trivariate model

\begin{tabular}{|c|c|c|c|}
\hline \multirow{2}{*}{$\begin{array}{c}\text { Estimated } \\
\text { parameter } \\
\hat{\mu}_{i}\end{array}$} & CROBEX & CROBIS & ERATE \\
\hline & $-9,15 \cdot 10^{-5 * *}$ & $-6,32 \cdot 10^{-6 * * *}$ & $-7,4 \cdot 10^{-7 * * *}$ \\
\hline$\hat{a}_{0, i}$ & $1,66 \cdot 10^{-6 * *}$ & $5,49 \cdot 10^{-8 * *}$ & $1,18 \cdot 10^{-8 * *}$ \\
\hline$\hat{a}_{1, i}$ & $0,0959^{* * *}$ & $0,0733^{* * *}$ & $0,0599^{* * *}$ \\
\hline$\hat{\beta}_{1, i}$ & $0,8789^{* * *}$ & $0,9132^{* * *}$ & $0,9293^{* * *}$ \\
\hline $\log L$ & 20540,99 & AIC & $-28,449$ \\
\hline \multirow{3}{*}{ SIC } & $-28,39$ & HQIC & $-28,429$ \\
\hline & $\hat{\rho}_{1,2}$ & $\hat{\rho}_{1,3}$ & $\hat{\rho}_{2,3}$ \\
\hline & $0,1275^{* * *}$ & $-0,0027$ & $-0,2622^{* *}$ \\
\hline
\end{tabular}

Note: ${ }^{* * *}$ stands for statistical significance on $1 \%$ level. $\hat{\mu}_{i}$ is the estimated value of expected return, Log L stands for log likelihood, AIC, SIC and HQIC for Akaike, Schwartz and Hanan-Quinn information criteria respectively. $\hat{\rho}_{1,2}, \hat{\rho}_{1,3}$ and $\hat{\rho}_{2,3}$ stand for correlation coefficients between CROBEX and CROBIS, CROBEX and exchange rate and $C R O B I S$ and exchange rate respectively. Multivariate autocorrelation test of standardized returns shows that there is no any autocorrelation up to lag 30 . Multivariate heteroskedasticity test of standardized returns shows that there is no any problem up to lag 30. Moreover, correlation coefficients of standardized residuals, covariances and covariances between squared residuals up to lag 30 of standardized residuals are not statistically significant. Strict positivity of each variance, as well as the condition for them to be finite is met as well as it can be seen in the table.

Source: Authors' calculation

Figure 1

Co-variances between three assets
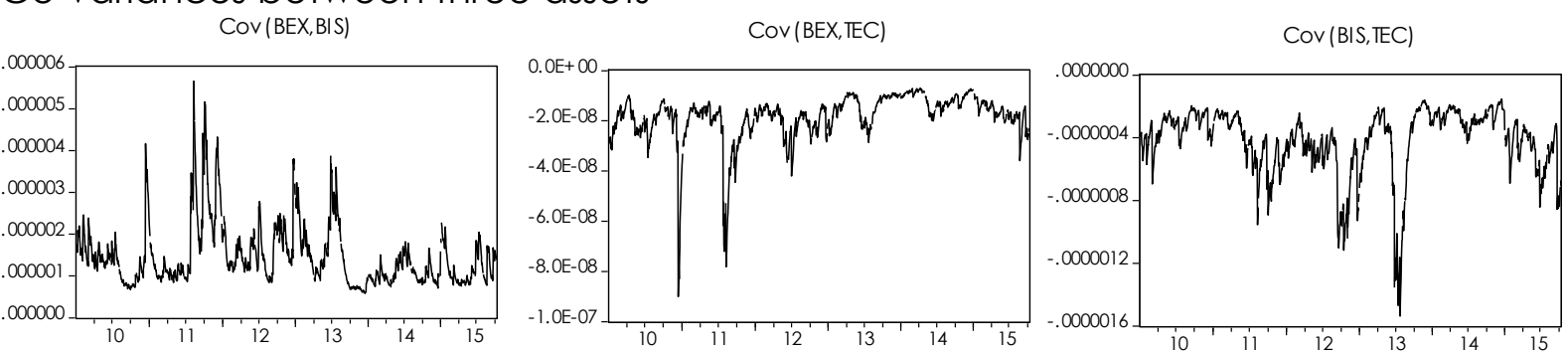

Note: BEX, BIS and TEC stand for CROBEX, CROBIS and exchange rate respectively.

Source: Authors' illustration

Using formula (4), optimal portfolio weights were calculated for each asset. The results are given on Figure 2. It is obvious that the share of CROBEX should have been the biggest compared to other two assets. The second biggest weight was CROBIS. This means that the investor should have, on average, invested the majority of his resources into stocks in the observed period. 
Figure 2

Share of each asset in portfolio

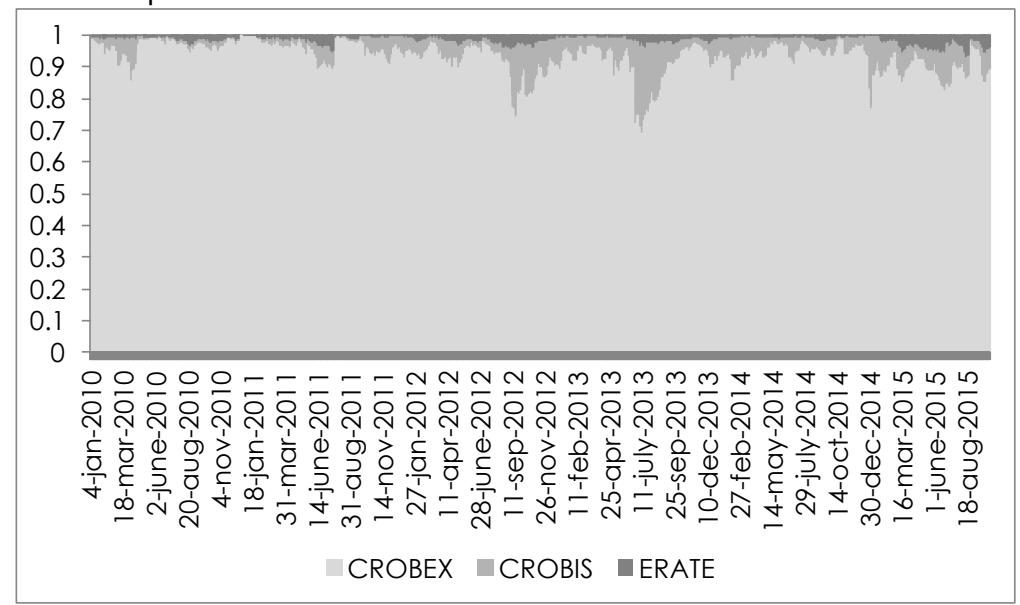

Source: Authors' illustration

In order to obtain answers if this portfolio formation and rebalancing is favourable for the investor, one average portfolio was simulated. In this portfolio we assume that investor buys equal weights of each asset. This portfolio is a benchmark for comparing the performance of MGARCH portfolio. Thus, each portfolio is simulated on a daily basis: average portfolio assumes that investors holds equal weights of each asset and MGARCH portfolio assumes that he rebalances the shares of each asset based upon figure 2. Expected portfolio returns have been calculated on a daily basis, as well as portfolio risks, in the Markowitz (1952) model framework. Figure 3 shows expected returns, where we can see that MGARCH portfolio realized bigger risks, which is not surprising due to the share of CROBEX in it as the most risky asset. Expected returns shown on Figure 4 indicate that this portfolio had smaller gains, but also smaller loses compared to the average portfolio. It seems by looking at these first results that the average portfolio performed better compared to the MGARCH one. Thus, more detailed statistics has been calculated for each portfolio and the results are shown in Table 3.

Figure 3

Portfolio risk of average and mgarch portfolios

AVERAGE

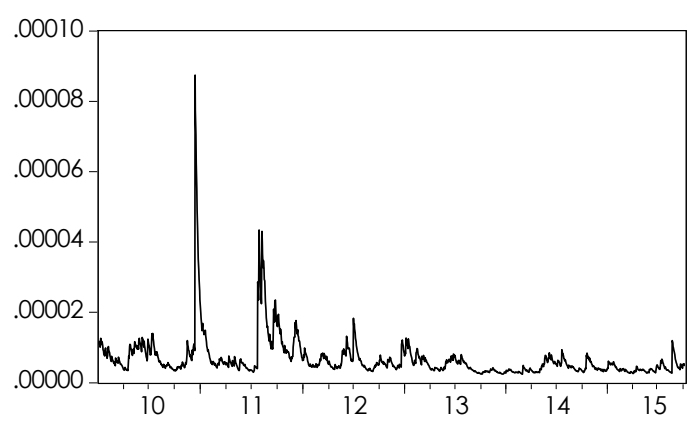

Source: Authors' illustration

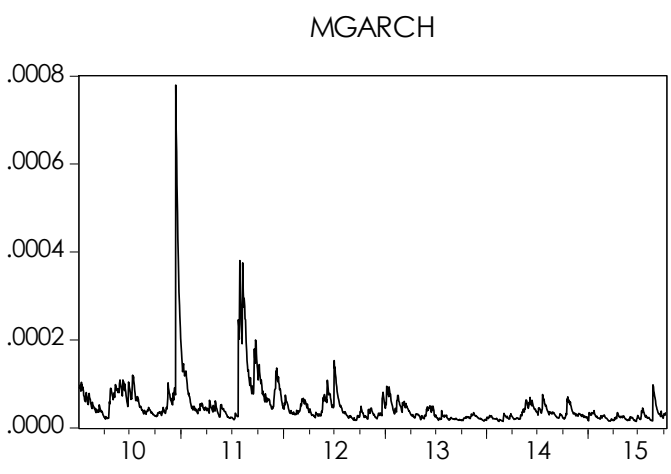


Figure 4

Expected return of average and mgarch portfolio AVERAGE
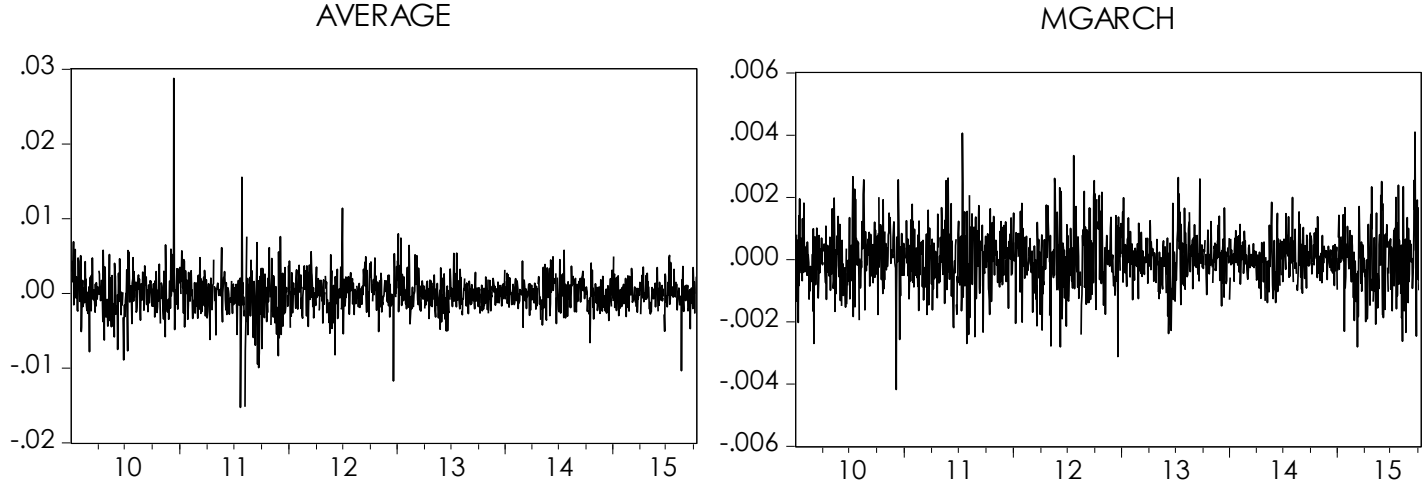

Source: Authors' illustration

In order to compare the performance of each portfolio, we calculated descriptive statistics for each portfolio's risk and return. Although the average portfolio risk was lower by comparing mean, median and other statistics in Table 3, the return of MGARCH portfolio performed better overall. This means that, on average, the mean expected return was bigger (it was positive compared to the negative expected return of average portfolio) and the occurred loses were smaller compared to the average portfolio. Moreover, in order to get more information on risk-return relationship, standardized returns were calculated for each portfolio in the observed period. They are basically the Sharpe ratio (Sharpe 1966) which gives us information on how much individual asset or portfolio achieves return by given one percent level of risk. In that way this measure is comparable for different types of assets or portfolios. Furthermore, it takes into account both risk and return when comparing portfolios. As it can be seen in Table 3, the MGARCH portfolio achieved overall a greater standardized return, whilst average portfolio realized losses. MGARCH portfolio had a smaller risk (standard deviation is lower) and realized losses were smaller compared to the average portfolio. Although, the maximum realized returns could have been achieved by average portfolio.

Table 3

Descriptive statistics for average and MGARCH portfolio

\begin{tabular}{|c|c|c|c|c|c|c|}
\hline \multirow{2}{*}{$\begin{array}{l}\text { Descriptive } \\
\text { statistics }\end{array}$} & \multicolumn{2}{|c|}{ Risk } & \multicolumn{2}{|c|}{ Return } & \multicolumn{2}{|c|}{ Standardized returns } \\
\hline & AVERAGE & MGARCH & AVERAGE & MGARCH & AVERAGE & MGARCH \\
\hline Mean & 0,0000068 & 0,0000506 & $-0,0000057$ & 0,0000277 & $-9,5028$ & 0,8916 \\
\hline Median & 0,0000051 & 0,0000350 & 0,0000147 & 0,0000291 & 2,6745 & 0,6869 \\
\hline $\begin{array}{l}\text { Standard } \\
\text { Deviation }\end{array}$ & 0,0000062 & 0,0000555 & 0,0025448 & 0,0009073 & 445,7626 & 29,0592 \\
\hline Minimum & 0,0000024 & 0,0000143 & $-0,0152834$ & $-0,0041751$ & $-3785,8998$ & $-149,7064$ \\
\hline Maximum & 0,0000875 & 0,0007796 & 0,0287788 & 0,0041000 & 3141,0486 & 150,6380 \\
\hline
\end{tabular}

Note: bolded numbers indicate the best performance Source: Authors' calculation

Finally, trading strategies were simulated in order to obtain final results whether it is useful to use the results of MGARCH methodology. It is assumed that investor invested in the average portfolio, by buying equal shares of each asset and he holds this portfolio until the end of the observed period. On the other hand, it is assumed that investor buys and sells each asset according to the shares of each asset given in 
Figure 2. Thus, in the first strategy he buys and holds the average portfolio. He can sell it in any point of time. In the second strategy, he restructures the portfolio each day with respect to the optimal portfolio weights from MGARCH model. Moreover, the simulations were made by assuming no transaction costs, and then by assuming $0,3 \%$ transaction costs, which is the lowest transaction cost which includes all of the costs investor has to deal with on Croatian financial market Škrinjarić (2013). Cumulative earning based upon the expected portfolio returns have been calculated and are shown on Figure 5. MGARCH portfolio trading strategy had on average an upward trend of achieving returns in the whole analyzed period, even when transaction costs were included. At the end of the period, this portfolio resulted with $4,01 \%$ earnings. On the other hand, if we observe earnings which could have been realized by the average portfolio, it can be seen that in the end a loss was realized (of $1,28 \%)$. Moreover, the volatility of average portfolio cumulative earnings is greater compared to MGARCH portfolio earnings. With MGARCH portfolio, investor did not have any sudden changes in the portfolio earnings, which was a more comforting situation. $81,50 \%$ of the time MGARCH portfolio earnings have surpassed the average portfolio earnings; $41,09 \%$ of the time average portfolio could have earned positive cumulated returns and the percentage rises for MGARCH portfolio up to $87,73 \%$. This tells us that although the possibilities of achieving great extreme returns with MGARCH portfolio were not as possible as with the average portfolio, the former portfolio enables the investor to earn positive returns at the end.

Figure 5

Cumulative earnings for average and mgarch portfolios

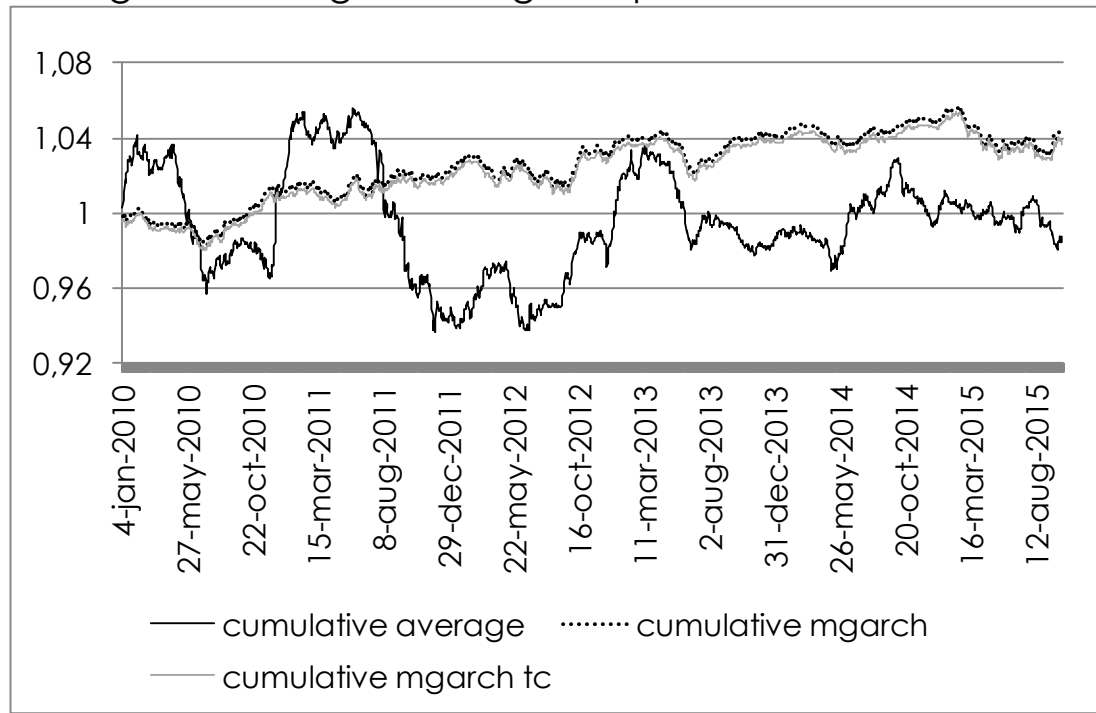

Note: tc stands for transaction costs included

Source: Authors' calculation

\section{Discussion}

Initial results using this methodology indicate that the stock market is the most sensitive to market shocks. CROBEX's alpha in univariate GARCH models was the biggest, which is not surprising since stocks are the most commonly traded financial assets in Croatia. New information which occurs in forms of market shocks thus results with a higher response of stock market compared to other two markets. The least responsive to market shocks is the exchange rate. Reasons could lie in the fact that the Croatian National Bank is keeping the exchange rate in fixed bands. This restricts bigger movements of exchange rate returns. All of this information tells investors that 
holding stocks in Croatia is more risky compared to exchange rate transactions in order to gain returns.

The persistency of market shocks in individual volatilities is the biggest for the exchange rate, and it is the least for stock market. This is consistent with the results given in Škrinjarić and Šego (2015). When we observed the correlation coefficients, it was found that the correlation between stock index and exchange rate was not statistically significant. This contributes to portfolio diversification purposes ("not holding all of your eggs in one basket"). Based upon Kroner and Ng (1998) methodology, optimal portfolio weights have been calculated for each asset for each trading day. Most of the portfolio should have been consisted of stocks, which is caused by risk-return relationship of each asset, but their interactions as well. In fact, investors mostly trade with stocks in Croatia. However, results show that other financial assets should be included in portfolios as well.

Comparing trading strategy and portfolio based upon MGARCH methodology and an average portfolio, it can be seen that the MGARCH portfolio is more risky. Reason lies in the fact that it holds the most risky asset in the greatest manner. However, the returns of the MGARCH portfolio have been less volatile compared to the average portfolio; with the less probability of gaining losses compared to the average portfolio. The purpose of the paper was to show this, that using MGARCH methodology enables the investor to have more control over portfolio risk and overall portfolio performance.

Finally, a comparison of cumulative earnings for each portfolio was made, with the inclusion of transaction costs. These costs can be very big on illiquid markets such as the Croatian one. However, the MGARCH portfolio outperformed the average portfolio in over $80 \%$ of the time. This indicates that using methodology described in this study can enhance portfolio selection in a great manner.

\section{Conclusion}

In this paper we have focused on using MGARCH methodology in portfolio selection. Previous literature has shown in the last decades that using this methodology in portfolio selection and rebalancing can enhance trading strategies in terms of risk and return. This study focused on portfolio selection by examining investing into stocks, bonds and exchange rates in Croatia for the period from January $4^{\text {th }} 2010$ to October 12 $12^{\text {th }}$ 2015. As it was shown in previous two sections, this methodology provides good guidance for a better trading strategy which could beat the market and other strategies as well.

If we compare the results in this study with previous research, the conclusions are very similar. Using the mentioned methodology enables the investor to achieve higher returns or manages risk better compared to an average portfolio. As in previous studies (especially those focusing on developing markets), there exists a time varying relationship between assets' risks and returns. This is not surprising because of the known characteristics of financial markets. However, there is a lack of studies which analyze stock, bond and exchange rate markets simultaneously. This is especially true for markets such as the Croatian financial markets. Finally, this study included transaction costs in the analysis. This is usually ignored in the literature, especially in the literature which deals with Croatian markets.

Investors can use MGARCH models to forecast future correlations and portfolio weights of assets in order to optimize their portfolios. They can achieve better earnings and smaller loses by employing the results from this methodology. However, there were some shortfalls of the study. Broad indices were used as proxies for individual financial markets. Sometimes, broad indices do not give us a full insight 
into a market. Moreover, we did not use any explanatory variables in the mean equation modelling. The reason lies in the fact that we wanted the system to be computationally less challenging to estimate. MGARCH methodology has a negative characteristic that it could have estimation problems with too many variables in the system. Since this is one of the first studies of this kind in Croatia, and on CEE countries as well, we hope to contribute to the existing literature by analyzing portfolio selection which takes into account risk-return interactions between different assets.

\section{References}

1. Aielli, G. P. (2013), "Dynamic Conditional Correlations: On Properties and Estimation", Journal of Business \& Economic Statistics, Vol. 31, No. 3, pp. 282-299.

2. Alexander, C. (2008), Practical Financial Econometrics, New York: John Wiley \& Sons.

3. Ang. A., Chen, J. (2005), "CAPM over the long run: 1926-2001", NBER Working Paper Series, National Bureau of Economic Research.

4. Bauwens, L., Laurent, S., Rombouts, J.V.K. (2006), "Multivariate GARCH Models: A Survey", Journal of Applied Econometrics, Vol. 21, pp. 79-109.

5. Bekaert, G., Hodrick, R. J., Zhang, X. (2009), "International Stock Return Comovements", The Journal of Finance, Vol. 64, No. 6, pp. 2591-2626.

6. Bollerslev T., Wooldridge J.M. (1992), "Quasi-maximum likelihood estimation and inference in dynamic models with time-varying covariances", Econometric Reviews, Vol. 11, pp. 143-172.

7. Bollerslev, T. (1990), "Modelling the coherence in short-run nominal exchange rates: A multivariate generalized ARCH model", Review of Economics and Statistics, Vol. 72, pp. 498-505.

8. Clements, A. E., Doolan, M. B., Hurn, A. S., Becker, R. (2012) "Selecting forecasting models for portfolio selection", NCER Working Paper Series.

9. CNB (2015), Croatian National Bank, http://www.hnb.hr, Accessed: October 15 th 2015.

10. Dajčman, S. (2013), "Dependence between Croatian, European stock markets A copula GARCH approach", Zbornik radova Ekonomskog fakulteta $\cup$ Rijeci, Vol. 31, No. 2, pp. 209-232.

11. Ding, Z., Engle, R. D. (2001) "Large Scale Conditional Covariance Matrix Modeling, Estimation and Testing", NYU Working Paper No. S-DRP-01-07.

12. Enders, W. (2015) Applied Econometric Time Series, $4^{\text {th }}$ Edition, New York: Wiley.

13. Engle, R. F. (2002), "Dynamic conditional correlation: A simple class of multivariate generalized autoregressive conditional heteroskedasticity models", Journal of Business \& Economic Statistics, Vol. 20, pp. 339-350.

14. Engle, R. F. (2009), Anticipating Correlations: A New Paradigm for Risk Management, New York: Princeton, Princeton University Press.

15. Gelos, R.G., Sahay, R. (2001), "Financial market spillovers in transition economies", Economics of Transition, Vol. 9, No. 1, pp. 53-86.

16. Hassan, S. A., Malik, F. (2007), "Multivariate GARCH modelling of sector volatility transmission" The Quarterly Review of Economics and Finance, Vol. 47, pp. 470480.

17. Hernández, M. A., Ibarra-Ramírez, R., Trupkin, D. R. (2011) "How Far Do Shocks Move Across Borders? Examining Volatility Transmission in Major Agricultural Futures Markets", Banco de México Working Papers, No 2011 1-15. 
18. Ho, K-Y.. Tsui, A. K. C. (2004), "An Analysis of the Sectoral Indices of Tokyo Stock Exchange: A Multivariate GARCH Approach with Time Varying Correlations", Stochastic Finance, Autumn School and International Conference.

19. Horvath, R., Petrovski, D. (2013), "International stock market integration: Central, South Easter Europe compared", Economic Systems, Vol. 37, pp. 81-91.

20. Katzke, N. (2013), "South African Sector Return Correlations: using DCC and ADCC Multivariate GARCH techniques to uncover the underlying dynamics", Stellenbosch Economic Working Papers, No. 17/13, University of Stellenbosch.

21. Kenourgios, D., Samitas, A. (2011), "Equity market integration in emerging Balkan markets", Research in International Business, Finance, Vol. 25, pp. 296-307.

22. Kroner, K. F., Ng, V. K. (1998), "Modeling asymmetric comovements of asset returns", Review of Financial Studies, Vol. 11, pp. 817-844.

23. Lien D., Tse Y. K. (2002), "Some recent developments in futures hedging", Journal of Economic Surveys, Vol. 16, pp. 357-396.

24. Longin F., Solnik B. (1995), "Is the correlation in international equity returns constant: 1960-1990?", Journal of International Money and Finance, Vol.14, pp. 3-26.

25. Longin, F., Solnik, B. (2001), "Extreme correlation in international equity markets", Journal of Finance, Vol. 6, pp. 649-676.

26. Lüketpohl, H. (2006), New Introduction to Multiple Time Series Analysis, Berlin: Springer.

27. Markowitz, H. (1952) "Portfolio selection", The Journal of Finance, Vol. 7, No. 1., pp. 77-91.

28. Righia, M. B., Ceretta, P. S. (2012), "Multivariate generalized autoregressive conditional heteroskedasticity (GARCH) modelling of sector volatility transmission: A dynamic conditional correlation (DCC) model approach", African Journal of Business Management, Vol. 6, No. 27, pp. 8157-8162.

29. Robbani, M. G., Bhuyan, R., Sbelti, W. M. (2013) "On the dynamics of volatility transmission: an empirical investigation on G-8 countries", Investment Management and Financial Innovations, Vol. 10, Issue 1, pp. 166-173.

30. Schotman, P. C., Zalewska, A. (2006), "Non-synchronous trading, testing for market integration in Central European emerging countries", Journal of Empirical Finance, Vol. 13, pp. 462-494.

31. Sharpe, W. F. (1966), "Mutual Fund Performance." Journal of Business, January 1966, pp. 119-138.

32. Škrinjarić, T. (2013), "Investicijske strategije prilagođene dnevnoj sezonalnosti u prinosima dionica", Ekonomska misao i praksa, Vol. 22, No. 1, pp. 97-120.

33. Škrinjarić, T. (2015), "Time varying CAPM betas on Zagreb Stock Exchange", Proceedings of the 13th International Symposium on Operational Research, pp. 413-418.

34. Škrinjarić, T., Šego, B. (2015), "Dynamic modeling of stock and bond return correlation in Croatia", Proceedings of the 13th International Symposium on Operational Research, pp. 419-424.

35. Syllignakis, M. N., Kouretas, G.P. (2011), "Dynamic correlation analysis of financial contagion: Evidence from the Central, Eastern European markets", International Review of Economics, Finance, Vol. 20, pp. 717-732.

36. Wang, P., Moore, T. (2008), "Stock market integration for the transition economies: time-varying conditional correlation approach", The Manchester School, Supplement 2008, pp.116-133.

37. ZSE (2015), Zagreb Stock Exchange, http://www.zse.hr, Accessed: October 15th 2015. 


\section{About the authors}

Tihana Škrinjarić is teaching and research assistant at Faculty of Economics and Business, University of Croatia. Currently, she is teaching 4 mathematical courses and is doing her PhD. Her field of study is applied financial econometrics, focusing on individual investor's aspect on markets. She won prizes Mijo Mirković and CRORS Best Young Researcher Paper Award in 2014, Rector's award in 2010, Dean's award in 2012 and 2009. She is author and co-author of 37 publications (books, scientific papers, etc.), among which some she presented on 6 international conferences. Author can be contacted at tskrinjaric@efzg.hr

Boško Šego is professor with full tenure at Faculty of Economics and Business, University of Croatia. Currently, he is teaching 7 mathematical courses. His field of study is financial mathematics and modelling. He won prize Mijo Mirković in 1987 and 2014. He is author and co-author of more than 100 publications (books, scientific papers, etc.), among which some he presented on dozens of international conferences. He was mentor for dozens of graduate thesis, master thesis and doctoral thesis. Author can be contacted at bsego@efzg.hr 